ISSN: 2638-6062

\title{
The Power of Addictions in Mexico
}

\author{
Gabriel Miranda Nava* \\ Department of Neurologist and Clinical Neurophysiologist, Centre Military Hospital, Mexico, USA

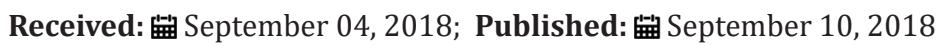

*Corresponding author: Gabriel Miranda Nava, Department of Neurologist and Clinical Neurophysiologist, Center Military Hospital, Sotelo, Mexico, USA

\section{Opinion}

Understanding an addiction simply and simply as that situation or element that cannot be detached due to the superlative gratification that leads us to adhere to that element; it is an exaggerated and pathological attachment, often irreversible, that entails sequels for life and that has many origins either biochemical or mental. Normally when we use the word addiction we refer to the use of "legal" substances, such as alcohol or tobacco, and illegal substances, such as cocaine, marijuana, amphetamines, solvents, etc., which have already become a problem of both health and public safety, for the clandestine sale of these substances. Afterwards, new elements are put on the table for this great family, since we will mention gambling addiction or addiction to gambling, addiction to sex, money, In Mexico, as we have said, unsuspected levels in addictions are already reached, with alcohol as the first example.

Do you know? that there are 52 types of diseases other than alcohol? That liver cirrhosis is a degenerative and deadly disease? The resulting monetary, labor and family costs? We know in the national survey of dictions that the intake of young people is increasing, it is also known that there is an increase in the number of women drinking and that people present complications at younger ages; $5.5 \%$ of the population has a harmful consumption of alcohol, which translates into around 6.5 million people, that is not counting the social drinker and the cover up by the family in the statistical reports. The snuff becomes the best news, since with the advent of taxes and the regulation of tobacco-free areas has been able to limit the number of addicts to the cigar; although the effects of longterm complications seen in emphysema and chronic bronchitis will be observed for a long time; the national survey against addictions shows $15.9 \%$ of the population for the year 2010 .

The paradigm of addictions are illegal substances, which go hand in hand with the violence and corruption of the clandestine market of them; for 2008, almost half a million people addicted to these substances were detected, led by marijuana and cocaine, which increased in their consumption and number of addicts, and the rest of the drugs remained at $1 \%$ that remained stable. ; and of course, complications, sequelae and effects on the patient and his family are a whole issue. In the following installments we will talk about the effects of each of the drugs, legal or illegal, so that they are known by you, dear readers and know how to avoid it, since some of your relatives or acquaintances may be submerged in these problems and many Sometimes when we realize it has been too late, yes, the "too late" is a recurring phrase in this type of suffering.
(C) (i) This work is licensed under Creative

To Submit Your Article Click Here: Submit Article

DOI: $10.32474 /$ PRJFGS.2018.02.000133

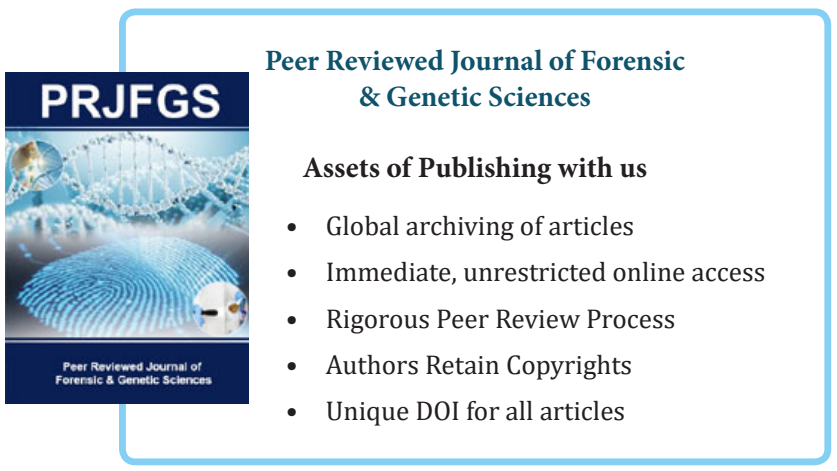

